\title{
Development of Simplex-PCR assays for Accurate Identification of Nine Staphylococcal Species at Genus and Species Levels
}

\author{
Bibek Ranjan Shome ${ }^{1}$, Krithiga Natesan ${ }^{1}$, Susweta Das Mitra ${ }^{1,2}$, Nimita Venugopal ${ }^{1}$, Bhuvana Mani ${ }^{1}$, \\ Feroze Ganaie ${ }^{1}$, Rajeswari Shome ${ }^{1}$, Habibur Rahman ${ }^{3}$ \\ ${ }^{1}$ ICAR-National Institute of Veterinary Epidemiology and Disease Informatics, Bengaluru, India \\ ${ }^{2}$ Department of Biotechnology, Dayanand Sagar University, Bengaluru, India \\ ${ }^{3}$ International Livestock Research Institute, New Delhi, India
}

\begin{abstract}
Objective: Species identification of Staphylococcus is the prerequisite for precise assessment of microbial dynamics including their transmission and pathogenic significance in the dairy herd environment. The present study aimed to develop simplex PCR assays for rapid and specific identification of nine different Staphylococcus species.
\end{abstract}

Methods: Specific primers targeting sodA gene for S. aureus, S. chromogenes, S. hominis, S. haemolyticus, S. hyicus; gap gene for S. sciuri, S. auricularis, S. simulans; and rdr gene for S. epidermidis were designed. The PCR assays were evaluated against 28 ATCC reference strains and 209 composite milk samples. Partial $16 S$ rRNA sequencing was performed to reconfirm the results.

Results: The PCR assays allowed species level identification of 348 staphylococcal field isolates recovered from 209 milk samples. The identification pattern was $S$. aureus $(n=101), S$. chromogenes $(n=89), S$. epidermidis $(n=57), S$. sciuri $(n=43), S$. haemolyticus $(n=34)$, S. hyicus $(n=13), S$. hominis $(n=5)$, S. auricularis $(n=3)$ and $S$. simulans $(n=3)$. The PCR based species identification was in $100 \%$ concordance with the partial $16 S$ rRNA gene sequencing approach.

Conclusion: The simplex PCR assays can be used as a precise tool for routine identification of Staphylococcus species from bovine milk as Staphylococcus species including coagulase-negative staphylococci is recognized a major cause of bovine mastitis in different parts of the world including India. J Microbiol Infect Dis 2018; 8(3):120-127

Keywords: $16 S$ rRNA gene sequencing, Staphylococcus, Species-specific PCR

\section{INTRODUCTION}

Bovine mastitis remains the foremost ailment of dairy cattle, causing economic losses up to 1.3 billion $\$$ to dairy farmers [1]. In spite of the fact, diverse organisms have been isolated from bovine mastitis, the epidemiology of bovine intra-mammary infection (IMI) has revealed a high prevalence of Staphylococcus [2,3]. Amongst Staphylococcus spp., Staphylococcus aureus is the major pathogen responsible for IMI. As of late, a shift has been seen in the microbial populace of the udder towards an increased occurrence of Coagulase Negative Staphylococci (CoNS) both in clinically healthy cows as well in cows influenced by mastitis and are designated as emerging pathogen in bovine mastitis [4,5]. However, the complete knowledge of CoNS species involved in bovine mastitis is still limited and benefits can accrue from having more reliable diagnostic methods for species identification [4]. In fact, the data pertaining to clinical significance, therapy and/or management of CoNS mastitis that depends on exact species identification is still inadequate [6]. Thus, owing to significant losses caused by mastitis to the dairy industry and the possible influence of the CoNS in the progression of this disease, precise and reliable strategies are required to unravel the diverse Staphylococcus spp. [5].

Pathogen detection has usually been based on traditional diagnostic methods that are

Correspondence: Dr. Bibek Ranjan Shome, ICAR-National Institute of Veterinary Epidemiology and Disease Informatics, Yelahanka, Bengaluru, India

Email: brshome29@gmail.com

Received: 28 April 2018 Accepted: 17 July 2018

Copyright (C JMID / Journal of Microbiology and Infectious Diseases 2018, All rights reserved 
immensely tedious, time-CoNSuming and often lack reliability. Besides, an intrinsic drawback of phenotypic strategies is the changeability in expression, interpretation and reproducibility of phenotypic characteristics $[6,7]$. In comparison, genotypic methods have superior resolving power and reproducibility. The advent of molecular techniques, especially, the DNA sequence-based methods have made the species identification of Staphylococcus more accurate as it is possible to compare with the reference database that aids in determining homology with the known species [6]. The partial 16S rRNA gene sequencing approach is well established gold standard method for the recognition and classification of wide-variety of organisms including Staphylococcus spp $[7,8]$. Although useful; however, this technique may not be feasible for routine identification as it is relatively expensive, time-CoNSuming and labor intensive. Therefore, a simple and dependable molecular test which provides a promising option for rapid and accurate identification of Staphylococcus species remains a necessity.

Hence, the present study targeted the Staphylococcus spp. commonly isolated from bovine milk namely $S$. aureus, $S$. chromogenes, S. epidermidis, S. sciuri, S. haemolyticus, S. simulans, $S$. hyicus, $S$. hominis, and $S$. auricularis for the development of simplex PCR targeting different genes.

\section{METHODS}

\section{Standard bacterial strains}

The type strains included 13 Staphylococcus spp. comprising of $S$. aureus and CoNS, and 15 strains of non-staphylococci that are phylogenetically related to genus Staphylococcus procured from American Type Culture Collection (Manassas, VA, USA) (Table 1).

\section{Sample collection}

The udder was cleaned thoroughly with an antiseptic solution and the teat ends were sanitized with swabs containing $70 \%$ alcohol. The foremilk was discarded and a total of 209 composite milk samples $(20 \mathrm{~mL}$ pooled, at the rate of $5 \mathrm{~mL} /$ quarter) were collected aseptically from all the lactating cows showing no apparent signs of mastitis from three dairy herds maintained in intensive, semi-intensive and/or extensive system in three villages in and around Bangalore, India. The milk samples were transported in a cold chain for laboratory processing.

\section{Isolation of Staphylococcus spp.}

Enrichment of each milk sample $(0.5 \mathrm{~mL})$ was carried out in brain heart infusion (BHI) broth for $6 \mathrm{~h}$ at $37{ }^{\circ} \mathrm{C}$. An inoculum of $10 \mu \mathrm{L}$ of each enriched sample was streaked on Gelatin Mannitol Salt Agar (Staphylococcus 110 medium; Himedia Laboratories, Mumbai, India) followed by incubation at $37{ }^{\circ} \mathrm{C}$ for $24 \mathrm{~h}$. pure cultures were obtained by subculturing on Brain Heart Infusion agar (Himedia Laboratories, Mumbai, India). Organisms suspected to be Staphylococcus on the basis of colony morphology, pigmentation, Gram staining, catalase and oxidase tests were stored frozen at $-40{ }^{\circ} \mathrm{C}$ in nutrient broth containing $15 \%$ glycerol for further confirmation.

\section{Genomic DNA extraction}

Genomic DNA from the overnight grown pure colonies were extracted using QIAamp DNA minikit (Qiagen, Düsseldorf, Germany) according to the manufacturer's recommendations. The concentration of the extracted DNA was determined spectrophotometrically using Nanodrop 2000C (Thermofischer Scientific Inc., Waltham, MA, USA) and stored at $-20{ }^{\circ} \mathrm{C}$ until use.

\section{Simplex PCR assays}

A Staphylococcus genus-specific PCR was devised. The genus-specific primer pair, flanking five hypervariable sequences (V3, V4, V5, V6, and V7) was designed to amplify 842 bp fragment of $16 S$ rRNA for the direct detection of the genus.

Simultaneously, based on the predominance of species distribution observed from partial gene sequencing analysis, species-specific PCR was developed for the major 9 species. Nine different species-specific primer sets were designed for $S$. aureus, S. chromogenes, S. epidermidis, S. sciuri, S. haemolyticus, S. hyicus, S. hominis, $S$. auricularis and $S$. simulans targeting different gene sequences available in the GenBank (Table 2). The specificity of each primer pair was checked with a panel of 28 reference ATCC strains comprising of Staphylococcus spp. and 
other bacteria phylogenetically close to Staphylococcus (Table 1). Simplex PCR assay for amplification of each organism was performed in $15 \mu \mathrm{L}$ reaction volume containing 1x PCR master mix (0.025 U Taq polymerase in reaction buffer, $2 \mathrm{mM} \mathrm{MgCl} 2,200 \mu \mathrm{M}$ deoxynucleotide triphosphates; Fermentas, Glen Burnie, MD, USA) and $50 \mathrm{ng}$ extracted DNA. The cycling conditions involved an initial denaturation at $94{ }^{\circ} \mathrm{C}$ for $5 \mathrm{~min}$, followed by 30 cycles of denaturation at $94{ }^{\circ} \mathrm{C}$ for $30 \mathrm{~s}$, annealing (temperature as in Table 2) for $30 \mathrm{~s}$ and extension at $72{ }^{\circ} \mathrm{C}$ for $45 \mathrm{~s}$ followed by final extension at $72{ }^{\circ} \mathrm{C}$ for $5 \mathrm{~min}$. The PCR products were analyzed by electrophoresis on a $1.5 \%$ agarose gel with $10 \mu \mathrm{g} \mathrm{mL}-1$ ethidium bromide and the results were visualized using a gel documentation system (Gbox, Syngene, UK).

\section{Species identification by partial 16S rRNA gene sequence analysis}

16S rRNA gene sequence analysis was performed for definitive species identification. Based on the multiple sequence alignment (http://www.ebi.ac.uk/Tools/clustalw2/index.html) variable regions of $16 S \mathrm{rRNA}$ were located and a primer pair flanking five hypervariable regions (V2, V3, V4, V5 and V6) was designed to amplify a $974 \mathrm{bp}$ fragment for the partial $16 S$ rRNA gene sequence analysis, using Primer 3 software (Table 1) [8]. All the isolated Grampositive bacteria were subjected to PCR for amplification of the $974 \mathrm{bp}$ fragment of the $16 \mathrm{~S}$ rRNA gene.

The PCR reaction setup and cycling conditions for amplification of each organism were similar as described in section 2.5 with $60{ }^{\circ} \mathrm{C}$ as the specific annealing temperature (Table 2). The amplified products were purified with QIAquick PCR purification kit (Qiagen, Duüsseldorf, Germany) and sequenced commercially (Eurofins Genomics, Bangalore, India) at both strands using the $\mathrm{ABI} 3730$ sequencer. The sequences were analyzed by comparing with those accessible in the GenBank using Blast search and edited with Chromas Lite 2.01 software (http://www.technelysium.com. au/chromas_lite.html). Match score of $>99 \%$ on nucleotide blast was acknowledged for the species identity. The sequences were submitted to the GenBank.
This study was conducted as per the applicable rules and regulations of good clinical practice. The study was approved by the independent institutional ethics committee of ICAR-NIVEDI.

\section{RESULTS}

\section{Isolation and identification of Staphylococcus spp.}

Out of 209 composite milk samples processed, a total of 400 catalase-positive Gram-positive cocci with smooth, pigmented colonies were isolated. Out of the 400 Gram-positive cocci, 348 isolates $(87 \%)$ were confirmed as Staphylococcus spp. by genus-specific PCR (Figure 1).

\section{Species-specific PCR}

The 9 different species-specific primers successfully amplified their respective species viz., S. aureus, S. chromogenes, S. epidermidis, S. sciuri, S. haemolyticus, S. hyicus, S. hominis, $S$. auricularis and $S$. simulans (Figure 2). The sequence analysis of selected ampliCoNS confirmed the amplification of the desired products. None of the oligonucleotide primers amplified with the other closely related Staphylococcus spp. or with other bacteria phylogenetically close to Staphylococcus. The distribution of 348 field isolates of Staphylococcus spp. were $S$. aureus $(n=101), S$. chromogenes $(n=89), S$. epidermidis $(n=57), S$. sciuri $(n=43), S$. haemolyticus $(n=34), S$. hyicus $(n=13)$, S. hominis $(n=5), S$. auricularis $(n=3)$ and S. simulans $(n=3)$ (Table 3$)$.

\section{Partial 16S rRNA gene sequence analysis}

The Partial 16S rRNA gene sequences obtained from the 348 Staphylococcus isolates indicated high sequence similarity (>99\%) with those sequences available in GenBank resulting in definitive identification of Staphylococcus spp. The speciation achieved by the partial $16 S$ rRNA gene sequence analysis was concordant with the PCR based identification results. All the staphylococcal partial $16 S$ rRNA gene sequences are available in GenBank (Table 3).

\section{Ethics}


Table 1. Evaluation of the specificity of the designed oligonucleotide primers using different Staphylococcus spp. and other phylogenetically closely related bacterial species.

\begin{tabular}{|c|c|c|c|c|c|c|c|c|c|c|}
\hline Reference ATCC cultures used & & $\begin{array}{l}\text { SAS2F } \\
\text { SAS2R }\end{array}$ & $\begin{array}{l}\text { SCHS1F } \\
\text { SCHS1R }\end{array}$ & $\begin{array}{l}\text { SHS2F } \\
\text { SHS2R }\end{array}$ & $\begin{array}{l}\text { SSCGF } \\
\text { SSCGR }\end{array}$ & $\begin{array}{l}\text { SERF } \\
\text { SERR }\end{array}$ & $\begin{array}{l}\text { SHYS1F } \\
\text { SHYS1R }\end{array}$ & $\begin{array}{l}\text { SHOS1F } \\
\text { SHOS1R }\end{array}$ & $\begin{array}{l}\text { SSIGF } \\
\text { SSIGR }\end{array}$ & $\begin{array}{l}\text { SAUGF } \\
\text { SAUGR }\end{array}$ \\
\hline S. aureus subsp. Aureus & ATCC12598 & + & - & - & - & - & - & - & - & - \\
\hline S. chromogenes & ATCC 43764 & - & + & - & - & - & - & - & - & - \\
\hline S. haemolyticus & ATCC 29970 & - & - & + & - & - & - & - & - & - \\
\hline S. sciuri subsp. Sciuri & ATCC 29062 & - & - & - & + & - & - & - & - & - \\
\hline S. epidermidis & ATCC 12228 & - & - & - & - & + & - & - & - & - \\
\hline S. hyicus & ATCC11249 & - & - & - & - & - & + & - & - & - \\
\hline S. hominis subsp. Hominis & ATCC 27844 & - & - & - & - & - & - & + & - & - \\
\hline S. simulans & ATCC 27848 & - & - & - & - & - & - & - & + & - \\
\hline S. cohnii subsp. Cohnii & ATCC 29974 & - & - & - & - & - & - & - & - & - \\
\hline S. xylosus & ATCC 12162 & - & - & - & - & - & - & - & - & - \\
\hline S. auricularis & ATCC 33753 & - & - & - & - & - & - & - & - & + \\
\hline S. saprophyticus & ATCC 15305 & - & - & - & - & - & - & - & - & - \\
\hline S. warneri & ATCC 27836 & - & - & - & - & - & - & - & - & - \\
\hline Streptococcus agalactiae & ATCC13813 & - & - & - & - & - & - & - & - & - \\
\hline Streptococcus dysgalactiae subsp. dysgalactiae & ATCC43078 & - & - & - & - & - & - & - & - & - \\
\hline Streptococcus uberis & ATCC19436 & - & - & - & - & - & - & - & - & - \\
\hline E. coli & ATCC 25922 & - & - & - & - & - & - & - & - & - \\
\hline Lactococcus lactis subsp. Lactis & ATCC11454 & - & - & - & - & - & - & - & - & - \\
\hline Salinicoccus roseus & ATCC 49258 & - & - & - & - & - & - & - & - & - \\
\hline Leuconostoc mesenteroides subsp. mesenteroides & ATCC 8293 & - & - & - & - & - & - & - & - & - \\
\hline Aerococcus viridians & ATCC11563 & - & - & - & - & - & - & - & - & - \\
\hline Micrococcus aurantiacus & ATCC 11731 & - & - & - & - & - & - & - & - & - \\
\hline Lactobacillus acidophilus & ATCC 4356 & - & - & - & - & - & - & - & - & - \\
\hline Pediococcus acidilactici & ATCC 25740 & - & - & - & - & - & - & - & - & - \\
\hline Planococcus citreus & ATCC 14404 & - & - & - & - & - & - & - & - & - \\
\hline Saccharococcus thermophilus & ATCC 43125 & - & - & - & - & - & - & - & - & - \\
\hline Gemella haemolysans & ATCC 10379 & - & - & - & - & - & - & - & - & - \\
\hline Macrococcus caseolyticus & ATCC 13548 & - & - & - & - & - & - & - & - & - \\
\hline
\end{tabular}

ATCC: American type culture collection. SAS2 Staph aureus; SCHS1, Staph chromogenes; SHS2, Staph haemolyticus; SSCG, Staph. sciuri; SER, Staph. epidermidis; SHYS1, Staph. hyicus; SHOS1, Staph. hominis; SSIG, Staph. simulans; SAUG, Staph. auricularis. 
Table 2. The details of oligonucleotide primers designed for genus- and species -specific identifications of Staphylococcus spp.

\begin{tabular}{|c|c|c|c|c|c|c|c|}
\hline Organism & $\begin{array}{l}\text { Target/ } \\
\text { gene }^{a}\end{array}$ & $\begin{array}{c}\text { GenBank } \\
\text { Nucleotide/Contig } \\
\text { Accession no. }\end{array}$ & $\begin{array}{c}\text { Primer } \\
\text { designation }\end{array}$ & Oligonucleotide primer $\left(5^{`}-3^{\prime}\right)$ & Location & $\begin{array}{l}\text { Amplicon size } \\
\text { (bp) }\end{array}$ & $\begin{array}{c}\text { Annealing temp. } \\
\left({ }^{\circ} \mathrm{C}\right)\end{array}$ \\
\hline \multirow{2}{*}{ Staphylococcus spp. } & \multirow{2}{*}{$16 S$ rRNA } & \multirow{2}{*}{ D83356 } & SG16P1F & GTG ATC GGC CAC ACT GGA & $285-302$ & \multirow{2}{*}{842} & \multirow{2}{*}{60} \\
\hline & & & SG16P1R ${ }^{b}$ & CAA CTT AAT GAT GGC AAC TAA GC & $1126-1104$ & & \\
\hline \multirow{2}{*}{ Staphylococcus spp. } & \multirow{2}{*}{$16 S$ rRNA } & \multirow{2}{*}{ D83356 } & SSEQIF $^{\mathrm{C}}$ & GCG GAC GGG TGA GTA ACA C & $78-96$ & \multirow{2}{*}{974} & \multirow{2}{*}{60} \\
\hline & & & SSEQIR ${ }^{c}$ & GAC GAC AAC CAT GCA CCA C & $1051-1033$ & & \\
\hline \multirow{2}{*}{ S. aureus } & \multirow{2}{*}{ 23S r RNA } & \multirow{2}{*}{ X68425 } & SAS2F & AGC GAG TCT GAA TAG GGC GTT T & $678-699$ & \multirow{2}{*}{894} & \multirow{2}{*}{56} \\
\hline & & & SAS2R & CCC ATC ACA GCT CAG ССТ TAA C & $1571-1550$ & & \\
\hline \multirow{2}{*}{ S. chromogenes } & \multirow{2}{*}{ SodA } & \multirow{2}{*}{ AJ343945 } & SCHS1F & GCG TAC CAG AAG ATA AAC AAA CTC & $134-157$ & \multirow{2}{*}{222} & \multirow{2}{*}{58} \\
\hline & & & SCHS1R & CAT TAT TTA CAA CGA GCC ATG C & $355-334$ & & \\
\hline \multirow{2}{*}{ S. haemolyticus } & \multirow{2}{*}{ SodA } & \multirow{2}{*}{ EU652775 } & SHS2F & CAA ATT AAA TTC TGC AGT TGA GG & $42-64$ & \multirow{2}{*}{531} & \multirow{2}{*}{58} \\
\hline & & & SHS2R & GGC CTC TTA TAG AGA CCA CAT GTT A & $572-548$ & & \\
\hline \multirow{2}{*}{ S. hyicus } & \multirow{2}{*}{ SodA } & \multirow{2}{*}{ AJ343913 } & SHYS1F & TAT TGA AGA GCT TAT CGC GAA TGT & $105-128$ & \multirow{2}{*}{215} & \multirow{2}{*}{58} \\
\hline & & & SHYS1R & ATC GTG CTG CTG CTT TAT CTG AG & $319-297$ & & \\
\hline \multirow{2}{*}{ S. epidermidis } & \multirow{2}{*}{$R d r$} & \multirow{2}{*}{ СР000029 } & SERF & AAG AGC GTG GAG AAA AGT ATC AAG & $400016-400039$ & \multirow{2}{*}{130} & 56 \\
\hline & & & SERR & TCG ATA CCA TCA AAA AGT TGG & $400145-400125$ & & 56 \\
\hline S sciuri & Gan & FU659914 & SSCGF & GAT TCC GCG TAA ACG GTA GAG & $122-142$ & 306 & 56 \\
\hline 0. serumt & map & L0000014 & SSCGR & CAT CAT TTA ATA CTT TAG CCA TTG GA & $427-402$ & 300 & 30 \\
\hline$S$ auricularis & Gap & AF495476 & SAUGF & TGC AAG GTC GTT TCA CAA GT & $127-146$ & 278 & 60 \\
\hline & & & SAUGR & TGT ACC ATC AAG TGT ATC GTG GT & $404-382$ & 210 & 00 \\
\hline S simulans & Gan & D०321698 & SSIGF & AGC TTC GTT TAC TTC TTC GAT TGT & $171-194$ & 472 & 60 \\
\hline S. Simulans & Gap & DQ 321698 & SSIGR & AAA AGC ACA AGC TCA CAT TGA C & $642-621$ & $4 / 2$ & 60 \\
\hline S. hominic & SodA & N7 AC P01000030 & SHOS1F & TTT TAA GCA AGA CAA TCG ACC TCA & $176518-176541$ & 727 & 60 \\
\hline S. $110 \mathrm{~m}$ mints & SOUA & NVL_ACLIVUTOU0000 & SHOS1R & CCA AAT TTA CCA TAT GCA GCA G & $177244-177223$ & $1<1$ & 00 \\
\hline
\end{tabular}

a sodA: superoxide dismutase $\mathrm{A}$; $r d r$ r ribonucleoside diphosphate reductase gene; gap: glyceraldehyde-3-Phosphate Dehydrogenase gene.

b Genus-specific.

c Primer for amplification of partial 16S rRNA gene for sequence based identification. 
Table 3. Distribution of identified Staphylococcus spp. from bovine milk samples from organised and unorganised dairy sectors.

\begin{tabular}{|c|c|c|c|c|c|c|}
\hline \multicolumn{7}{|c|}{ Organised Farms } \\
\hline & $\operatorname{farmA}(30)^{a}$ & farmB (42) ${ }^{a}$ & $\operatorname{farmC}(61)^{a}$ & unorganised sector (76) $^{a}$ & Total & GenBank accession no \\
\hline \multicolumn{7}{|l|}{ Species } \\
\hline S. aureus & 8 & 10 & 68 & 15 & 101 & HM452003-2094 \\
\hline \multirow[t]{2}{*}{ S. chromogenes } & - & 15 & 36 & 38 & 89 & НМ367743-7826 \\
\hline & & & & & & HM452095-2099 \\
\hline \multirow[t]{2}{*}{ S. epidermidis } & 12 & 9 & 29 & 7 & 57 & HM367827-7875 \\
\hline & & & & & & HM452104-2111 \\
\hline \multirow[t]{3}{*}{ S. sciuri } & - & 9 & 25 & 9 & 43 & HM451958-1991 \\
\hline & & & & & & HM451994-1999 \\
\hline & & & & & & HM452101-2103 \\
\hline \multirow[t]{2}{*}{ S. haemolyticus } & 4 & 11 & 12 & 7 & 34 & HM359218-9243 \\
\hline & & & & & & HM452114-2121 \\
\hline S. hyicus & - & 8 & - & 5 & 13 & HM451942-1954 \\
\hline S. hominis & - & - & 5 & - & 5 & HM451928-1932 \\
\hline S. auricularis & - & 3 & - & - & 3 & HM451939-1941 \\
\hline \multirow[t]{3}{*}{ S. simulans } & - & 3 & - & - & 3 & HM452000 \\
\hline & & & & & & HM452100 \\
\hline & & & & & & HM462053 \\
\hline
\end{tabular}

a Number of cows screened are in parentheses. 


\section{DISCUSSION}

The general learning of the CoNSortia group and the significance of the causative agents in bovine mastitis stay feeble as most investigations to date were compelled by the CoNStraints of traditional microbiological methods $[9,10]$. Despite the high prevalence of Staphylococcus spp. especially the CoNS as the main pathogen causing bovine intramammary infection (IMI) in numerous nations, still a precise, quick and advantageous method that can differentiate between the bacterial species of this family is not available [11]. Though phenotypic identification of CoNS is widely used, molecular assays have been appeared to be more discriminatory between the CoNS species [12].

The gene sequencing approach, as a last resort for unambiguous identification, provides an exact molecular identification of CoNS species, specifically through sequencing of hsp60, tuf, rpoB, $16 S$ rRNA, sodA, dnaJ, and/or gap gene $[5,13,14]$. However, this strategy may not be feasible for routine identification on daily basis in clinical diagnostic set-up, since it is timeCoNSuming, labor-intensive, and economically unviable for analysis of a large number of isolates. In order to overcome these limitations, a PCR based identification protocol was standardized in the present study for 9 different Staphylococcus spp.

For genus-level identification of Staphylococcus, analysis of partial $16 S$ rRNA gene sequence was carried out targeting hypervariable regions V2 and V3 which allows differentiation between organisms across all major phyla of bacteria [15]. Accordingly, the genus Staphylococcus was identified using a novel set of the 16S rRNA gene specific primer designed in the present study. For bacterial phylogeny and taxonomy, 16S rRNA is the most commonly targeted gene. However, it does not possess adequate discriminatory ability to differentiate all the species within the genera Staphylococcus [6, 13,16]. Hence, several studies have been reported on species identification system based on other target regions mainly housekeeping genes like cpn60 (chaperonin or heat shock protein 60), sodA [16,17], gap [16], tuf [18] for differentiation of Staphylococcus spp. Besides, the 16S-23S rRNA intergenic spacer region is also useful for identification of strains as it suffers lesser evolutionary pressure [19]. Similarly, the sodA gene was found to CoNStitute a highly discriminative target sequence for differentiating closely related bacterial species $[3,20]$. Ghebremedhin et al., suggested gap gene to be an ideal target even for taxonomic analysis of Staphylococcus spp. [16]. Accordingly, in the present study, 9 different species-specific PCR primers were targeted for the important staphylococcal species. Species-specific PCR assay targeting the DNA sequences showing potential discriminatory power namely, sodA gene for $S$. aureus, S. chromogenes, S. hominis, $S$. haemolyticus, $S$. hyicus; gap gene for $S$. sciuri, $S$. auricularis, S. simulans; and $r d r$ gene for $S$. epidermidis was developed. The PCR was verified on 348 field isolates and evaluation with the 28 standard ATCC strains confirmed the specificity of the primers, thereby, eliminating the likelihood of any kind of misidentification.

Subsequently, to validate the accuracy and reliability of the described assays, the partial 16S rRNA gene sequence analysis, a methodology broadly acknowledged as a standard technique for identification of Staphylococcus spp. as well as other microorganisms was utilized [21]. The observations achieved using partial $16 S$ rRNA gene sequence analyses were concordant with the speciesspecific PCR results confirming the accuracy of the primers and the PCR protocol developed.

In conclusion, the PCR assays described in this study were demonstrated to be a valuable and efficient tool for swift and specific identification of 9 Staphylococcus spp. In view of the fact that appropriate species identification is imperative for curbing the mastitis burden and monitor epidemiological profile, this species-specific PCR will prove to be a satisfactory tool for the identification of the common staphylococcal species, independent of their phenotypic traits. In turn, identification of bacteria will help to determine an effective antimicrobial treatment as well to monitor and control the rate of infection at the farm level. Besides, the assay may likewise be utilized for the quality control of milk and other edibles in addition to the detection of this pathogen in clinical and ecological settings [22].

\section{ACKNOWLEDGMENTS}


Financial Disclosure: This study was funded by grants from National Agricultural Innovative Project (NAIP), Indian Council of Agricultural Research, New Delhi, Government of India, under Component 4: Basic and Strategic Research to BRS (NAIP/Comp4/C-30017/2008-09).

Declaration of Conflicting Interests: The authors declare that they have no conflict of interest.

\section{REFERENCES}

1. Bansal BK, Gupta DK. Economic analysis of bovine mastitis in India and Punjab - A Review. Ind J Dai Sci 2009; 62:337-344.

2. Sumathi BR, Veeregowda BM, Gomes AR. Prevalence and antibiogram profile of bacterial isolates from clinical bovine mastitis. Vet World 2008; $1: 237-238$.

3. Shome BR, Mitra SD, Bhuvana M, et al. Multiplex PCR assay for species identification of bovine mastitis pathogens. J Appl Microbiol 2011; 111:1349-1356.

4. Pyorala S, Taponen S. Coagulase-negative staphylococci- emerging mastitis pathogens. Vet Microbiol 2009; 134:3-8.

5. Braem G, De Vliegher S, Supre K, Haesebrouck $F$, Leroy $F$, De Vuyst L. (GTG)5-PCR fingerprinting for the classification and identification of coagulasenegative Staphylococcus species from bovine milk and teat apices: A comparison of type strains and field isolates. Vet Microbiol 2011; 147:67-74.

6. Zadoks RN, Watts JL. Species identification of coagulase-negative staphylococci: genotyping is superior to phenotyping. Vet Microbiol 2009; 134:20-28.

7. Park JY, Fox LK, Seo KS, et al. Comparison of phenotypic and genotypic methods for the species identification of coagulase-negative staphylococcal isolates from bovine intramammary infections. Vet Microbiol 2011; 147:142-148.

8. Rozen S, Skaletsky HJ. Primer-3 on the WWW for general users and for biologist programmers. In: Krawetz S, Misener S (Eds) Bioinformatics Methods and Protocols: Methods in Molecular Biology, Humana Press, Totowa, USA; 2000.p.365-386.

9. Kuang Y, Tani K, Synnott AJ, et al. Characterization of bacterial population of raw milk from bovine mastitis by culture- independent PCRDGGE method. J Biochem Engg 2009; 45:76-81.

10. Cremonesi P, Pisoni G, Severgnini M, et al. Pathogen detection in milk samples by ligation detection reaction-mediated universal array method. J Dairy Sci 2009; 92:3027-3039.

11. Supre K, Haesebrouck F, Zadoks RN, Vaneechoutte M, Piepers S, De Vliegher S. Some coagulase-negative Staphylococcus species affect udder health more than others. J Dairy Sci 2011 ; 94:2329-2340.

12. Patteet L, Goossens $H$, leven M. Validation of the MicroScan-96 for the species identification and methicillin susceptibility testing of clinical significant coagulase-negative staphylococci. Eur J Clin Microbiol Infect Dis 2012;31:747-751.

13. Shah MM, lihara $H$, Noda $M$, et al. DnaJ gene sequence-based assay for species identification and phylogenetic grouping in the genus Staphylococcus. Int J Syst Evol Microbiol 2007;57:25-30.

14. Supre K, De-Vliegher S, Sampimon OC, et al. Use of transfer RNA-intergenic spacer PCR combined with capillary electrophoresis to identify coagulasenegative Staphylococcus species originating from bovine milk and teat apices. J Dairy Sci 2009; 92:3204-3210.

15. Chakravorty S, Helb D, Burday M, Connell C, Alland D. A detailed analysis of $16 \mathrm{~S}$ ribosomal RNA gene segments for the diagnosis of pathogenic bacteria. J Microbiol Methods 2007; 69:330-339.

16. Ghebremedhin B, Layer F, Konig W, Konig B. Genetic classification and Distinguishing of Staphylococcus Species Based on Different Partial gap, 16S rRNA, hsp60, rpoB, sodA and tuf gene sequences. J Clin Microbiol 2008; 46:1019-1025.

17. Heikens E, Fleer A, Paauw A, Florijn AC, Fluit AC. Comparison of genotypic and phenotypic methods for species-level identification of clinical isolates of coagulase-negative staphylococci. J Clin Microbiol 2005; 43:2286-2290.

18. Capurro A, Artursson K, Waller KP, Bengtsson B, Ericsson-Unnerstad $\mathrm{H}$, Aspan $\mathrm{A}$. Comparison of a commercialized phenotyping system, antimicrobial susceptibility testing, and tuf gene sequence-based genotyping for species-level identification of coagulase-negative staphylococci isolated from cases of bovine mastitis. Vet Microbiol 2009; 134:327-333

19. Gurtler V, Stanisich VA. New approaches to typing and identification of bacteria using the 16S-23S rDNA spacer region. Microbiol 1996; 142:3-16.

20. Poyart C, Quesne G, Boumaila C, Trieu-cuot P. Rapid and accurate species-level identification of coagulase-negative staphylococci by using the $\operatorname{sod} A$ gene as a target. J Clin Microbiol 2001; 39:42964301.

21. Becker K, Harmsen D, Mellmann A, et al. Development and evaluation of a quality-controlled ribosomal sequence database for $16 \mathrm{~S}$ ribosomal DNA-based identification of Staphylococcus species. J Clin Microbiol 2004; 42:4988-4995.

22. Schukken YH, Gonzalez RN, Tikofsky LL, et al. CNS mastitis: Nothing to worry about? Vet Microbiol 2009:134:9-14. 